\title{
Efficacy of Oral Administration of Praziquantel and Mebendazole against Microcotyle sebastis (Monogenea) Infestation of Cultured Rockfish (Sebastes schlegeli)
}

\author{
Ki Hong Kim¹,3, Soo-Il Park ${ }^{* 1}$ and Bo-Young Jee*2 \\ ${ }^{* 1}$ Department of Aquatic Life Medicine, Pukyong National University, 599-1 Dae Yeon \\ Dong, Nam Ku, Pusan 608-737 \\ *2Pathology Division, National Fisheries Research and Development Institute, \\ Pusan 619-900, Republic of Korea
}

(Received July 16, 1998)

\begin{abstract}
The efficacy of praziquantel and mebendazole against Microcotyle sebastis infestation in juvenile rockfish by oral administration was evaluated at low $\left(10 \pm 1^{\circ} \mathrm{C}\right)$ and high $\left(20 \pm 1^{\circ} \mathrm{C}\right)$ water temperatures. Oral administration of praziquantel or mebendazole resulted in significant reduction or complete extermination of $M$. sebastis infestation in juvenile rockfish. The treatment efficacy of praziquantel $200 \mathrm{mg} / \mathrm{kg} \mathrm{B}$. W. at both temperatures $\left(10^{\circ} \mathrm{C}\right.$ and $\left.20^{\circ} \mathrm{C}\right)$ and mebendazole $200 \mathrm{mg} / \mathrm{kg} \mathrm{B}$. W. at $20^{\circ} \mathrm{C}$ was $100 \%$. Praziquantel was more effective against M. sebastis than mebendazole at $10^{\circ} \mathrm{C}$. Our results strongly suggest that oral administration of praziquantel and mebendazole can be used practically in netpen-culture of rockfish as an effective control measure against $M$. sebastis infestations without imposing handling-related stress to fish.
\end{abstract}

Key words: praziquantel, mebendazole, oral administration, Microcotyle sebastis, Sebastes schlegeli

Microcotyle sebastis is an important ectoparasite on the gills of rockfish, Sebastes schlegeli, reared in netpens in Korea. Because of lacking successful management and treatment strategies to prevent and control this parasite, extensive mortalities of juvenile rockfish have occurred every year.

Various chemicals including formalin, copper sulfate (Thoney, 1990), potassium permanganate (Chan and Wu, 1984), hydrogen peroxide (Kabata, 1985), trichlorfon (Imada and Muroga, 1979; Thoney, 1990) have been employed to control monogenean parasites. However, many of them were proved detrimental to fish and/ or environment, and most were not $100 \%$ effective (Thoney and Hargis, 1991). Recently, praziquantel and mebendazole developed to treat various internal helminth infections in mammals have been used to treat monogenean diseases in aquaculture (Goven and Amend, 1982; Schmahl and Mehlhorn, 1985; Székely and Molnár, 1987, 1990; Buchmann, 1987, 1993; Buchmann and Bjerregaard, 1990; Buchmann et al., 1990; Mellergaard, 1990).

\footnotetext{
*3 Corresponding author

E-mail: khkim@dolphin.pknu.ac.kr
}

To date, only bath treatments with those chemotherapeutants have been used to control monogenean diseases. The bath treatment of rockfish in netpens, however, requires additional labour and is stressful to the fish. Thus, other effective methods are needed to control $M$. sebastis of rockfish. Recently, Kim and Choi (1998) reported that oral administrations of mebendazole and bithionol were effective in treating $M$. sebastis infestations in cultured rockfish.

The aim of the present study was to determine the efficacy of praziquantel and mebendazole against $M$. sebastis infestation by oral administration, and to compare the efficacy of the both compounds at low $\left(10^{\circ} \mathrm{C}\right)$ and high $\left(20^{\circ} \mathrm{C}\right)$ water temperatures.

\section{Materials and Methods}

Fish

Netpen reared juvenile rockfish (body length: 8-13 $\mathrm{cm}$ ) were obtained from a local producer in Tongyoung (endemic area of $M$. sebastis), Korea. The presence of $M$. sebastis on the gills was confirmed by examination of 10 fish. The prevalence was $100 \%$, and the intensity was $54.2 \pm 32.8$. A total of 150 juvenile rockfish 
was randomly divided into a low water temperature $\left(10 \pm 1^{\circ} \mathrm{C}\right)$ and a high water temperature group $(20 \pm$ $1^{\circ} \mathrm{C}$ ), then separated again into 5 groups of 15 fish in each temperature group. The fish were acclimated to $10 \pm 1^{\circ} \mathrm{C}$ or $20 \pm 1^{\circ} \mathrm{C}$ for 2 weeks prior to the experiment in a flow-through laboratory system. The water temperature was adjusted by means of cooling and heating devices. Fish were fed commercial pelleted rockfish food ( $1.0 \%$ of body weight per day) throughout the experiment. The volume of each experimental aquarium was $50 \mathrm{l}$, and flow rate was maintained at approximately $0.2 \mathrm{l} / \mathrm{min}$ under the condition of $16 \mathrm{~L}: 8 \mathrm{D}$. The seawater had a salinity of $33 \%$.

\section{Treatment}

Fish were anaesthetized with benzocaine and were intubated directly onto the stomach with varying concentrations of the test chemotherapeutants. In each temperature regime, one group was fed with $100 \mathrm{mg}$ praziquantel (Shinpoong Pharm. Co. Ltd.)/kg B. W., and the second group $200 \mathrm{mg}$ praziquantel $/ \mathrm{kg} \mathrm{B}$. W. The third group $100 \mathrm{mg}$ mebendazole (Sigma)/kg B. W., and the fourth group $200 \mathrm{mg}$ mebendazole/kg B. W. The fish in the control group were given $0.8 \%$ saline (Table 1). The effectiveness of each treatment was confirmed by the comparison of the number of parasites in each treatment group with those in the control group at 7 days post-treatment. Abundance and prevalence were determined according to the methods given in Margolis et al. (1982).

\section{Statistical analysis}

All data were analyzed using Mann-Whitney's U-test
(SPSS 7.5 for Windows, SPSS Inc.).

\section{Results}

Oral administration of praziquantel or mebendazole resulted in significant reduction or completely extermination of $M$. sebastis infestations in juvenile rockfish, irrespective of the different dosages and water temperatures (Table 1). The treatment efficacy of praziquantel $200 \mathrm{mg} / \mathrm{kg} \mathrm{B}$. W. at both temperatures $\left(10 \pm 1^{\circ} \mathrm{C}\right.$ and 20 $\pm 1^{\circ} \mathrm{C}$ ) and mebendazole $200 \mathrm{mg} / \mathrm{kg} \mathrm{B}$. W. at $20 \pm 1^{\circ} \mathrm{C}$ was $100 \%$. No apparent abnormalities were noticed in the experimental fish during the experimental period.

At $10 \pm 1^{\circ} \mathrm{C}$, statistically significant differences in treatment efficacy were revealed between praziquantel and mebendazole (Table 2). Praziquantel was more effective against $M$. sebastis than mebendazole at $10 \pm$ $1^{\circ} \mathrm{C}$. At $20 \pm 1^{\circ} \mathrm{C}$, however, there was no significant difference in treatment efficacy between praziquantel and mebendazole at each equal dosage.

Praziquantel was highly effective against $M$. sebastis at both temperatures. No statistically significant difference in treatment efficacy of praziquantel was revealed between $10^{\circ} \mathrm{C}$ and $20^{\circ} \mathrm{C}$ at each equal dosage (Table 2). On the other hand mebendazole showed a temperature-dependent exterminating property. The efficacy of mebendazole against $M$. sebastis was considerably higher at the higher water temperature.

There were significant differences in treatment efficacy between the two different dosages of praziquantel at both temperatures (Table 2). The efficacy of mebendazole was not significantly different between the two different dosages at $10 \pm 1^{\circ} \mathrm{C}$, but was significantly

Table 1. Efficacy of oral administration of praziquantel and mebendazole against Microcotyle sebastis infestation in juvenile rockfish

\begin{tabular}{|c|c|c|c|c|c|c|}
\hline $\begin{array}{l}\text { Water } \\
\text { Temp. }\end{array}$ & $\begin{array}{l}\text { Experimental } \\
\text { group }\end{array}$ & $\begin{array}{c}\text { Dosages } \\
\text { (mg/kg B. W.) }\end{array}$ & $\begin{array}{c}\text { No. of } \\
\text { rockfish } \\
\text { examined }\end{array}$ & $\begin{array}{c}\text { Prevalence } \\
(\%)\end{array}$ & $\begin{array}{c}\text { Abundance } \\
\text { (Mean } \pm \\
\text { S.D.) }\end{array}$ & $\begin{array}{c}\text { Range of } \\
\text { parasite } \\
\text { number }\end{array}$ \\
\hline \multirow[t]{5}{*}{$10 \pm 1^{\circ} \mathrm{C}$} & Control & Only saline & 15 & 100.0 & $56.9 \pm 39.3$ & $3-136$ \\
\hline & Praziquantel & 100 & 15 & 66.7 & $1.9 \pm 2.3$ & $0-6$ \\
\hline & & 200 & 15 & 0 & 0 & 0 \\
\hline & Mebendazole & 100 & 15 & 100.0 & $16.7 \pm 14.8$ & $2-49$ \\
\hline & & 200 & 15 & 86.7 & $12.3 \pm 10.8$ & $0-38$ \\
\hline \multirow[t]{5}{*}{$20 \pm 1^{\circ} \mathrm{C}$} & Control & Only saline & 15 & 100.0 & $58.7 \pm 36.1$ & $5-122$ \\
\hline & Praziquantel & 100 & 15 & 66.7 & $1.5 \pm 1.8$ & $0-\quad 7$ \\
\hline & & 200 & 15 & 0 & 0 & 0 \\
\hline & Mebendazole & 100 & 15 & 60.0 & $4.1 \pm 6.4$ & $0-24$ \\
\hline & & 200 & 15 & 0 & 0 & 0 \\
\hline
\end{tabular}


Table 2. The values of significance among experimental groups calculated using Mann-Whitney's U-test

\begin{tabular}{ccccccccccc}
\hline \hline Group & LC & LP1 & LP2 & LM1 & LM2 & HC & HP1 & HP2 & HM1 & HM2 \\
\hline LC & S & 0.000 & 0.000 & 0.002 & 0.000 & 0.901 & 0.000 & 0.000 & 0.000 & 0.000 \\
LP1 & & S & 0.000 & 0.000 & 0.001 & 0.000 & 0.863 & 0.000 & 0.579 & 0.000 \\
LP2 & & & $\mathrm{S}$ & 0.000 & 0.000 & 0.000 & 0.003 & $\mathrm{~S}$ & 0.001 & $\mathrm{~S}$ \\
LM1 & & & & $\mathrm{S}$ & 0.467 & 0.001 & 0.000 & 0.000 & 0.001 & 0.000 \\
LM2 & & & & & $\mathrm{S}$ & 0.000 & 0.000 & 0.000 & 0.007 & 0.000 \\
HC & & & & & & $\mathrm{S}$ & 0.000 & 0.000 & 0.000 & 0.000 \\
HP1 & & & & & & & $\mathrm{S}$ & 0.000 & 0.368 & 0.000 \\
HP2 & & & & & & & & $\mathrm{S}$ & 0.001 & $\mathrm{~S}$ \\
HM1 & & & & & & & & & $\mathrm{S}$ & 0.001 \\
\hline
\end{tabular}

[LC: Control $\left(10 \pm 1^{\circ} \mathrm{C}\right), \mathrm{LP} 1$ : Praziquantel $100 \mathrm{mg} / \mathrm{kg} \mathrm{B}$. W. $\left(10 \pm 1^{\circ} \mathrm{C}\right), \mathrm{LP} 2$ : Praziquantel $200 \mathrm{mg} /$ kg B. W. $\left(10 \pm 1^{\circ} \mathrm{C}\right), \mathrm{LM} 1$ : Mebendazole $100 \mathrm{mg} / \mathrm{kg} \mathrm{B}$. W. $\left(10 \pm 1^{\circ} \mathrm{C}\right), \mathrm{LM} 2$ : Mebendazole $200 \mathrm{mg} /$ kg B. W. $\left(10 \pm 1^{\circ} \mathrm{C}\right), \mathrm{HC}$ : Control $\left(20 \pm 1^{\circ} \mathrm{C}\right), \mathrm{HP} 1$ : Praziquantel $100 \mathrm{mg} / \mathrm{kg} \mathrm{B}$. W. $\left(20 \pm 1^{\circ} \mathrm{C}\right), \mathrm{HP} 2$ : Praziquantel $200 \mathrm{mg} / \mathrm{kg} \mathrm{B}$. W. $\left(20 \pm 1^{\circ} \mathrm{C}\right), \mathrm{HM}$ : Mebendazole $100 \mathrm{mg} / \mathrm{kg} \mathrm{B}$. W. $\left(20 \pm 1^{\circ} \mathrm{C}\right), \mathrm{HM} 2$ : Mebendazole $200 \mathrm{mg} / \mathrm{kg} \mathrm{B}$. W. $\left(20 \pm 1{ }^{\circ} \mathrm{C}\right)$, S: Same data]

different $(p<0.05)$ at $20 \pm 1^{\circ} \mathrm{C}$.

\section{Discussion}

The results clearly show that oral administrations of praziquantel or mebendazole are effective for controlling Microcotyle sebastis infesting the gills of cultured rockfish. Praziquantel has a very broad spectrum of activity against trematodes and cestodes infections in mammals (Andrew et al., 1983), and has recently been employed to control monogenean diseases in fish by bath treatment. Although praziquantel has been injected or given orally to eliminate endoparasitic helminths such as metacercariae of Diplostomum spathaceum infecting eye lenses of trout (Bylund and Sumari, 1981), Clinostomum marginatum infecting muscle of channel catfish (Lorio, 1989) and adult cestodes of both freshwater and marine fishes (Pool et al., 1984; Moser et al., 1986; Sanmartin Duran et al., 1989), it has never been used to treat monogenean diseases by oral administration. In the present study, we report for the first time that oral administration of praziquantel is a very effective method in treatment of infections with gill monogeneans. Mebendazole is a member of the benzimidazole group commonly used against nematodes infections in mammals (Roberson, 1982) but previously shown to be potent against fish monogeneans by bath treatment (Goven and Amend, 1982; Székely and Molnár, 1987; Buchmann, 1993; Buchmann and Bjerregaard, 1990; Mellergaard, 1990). According to the results of Kim and Choi (1998), oral administration of mebendazole at a dosage of $100 \mathrm{mg} / \mathrm{kg} \mathrm{B}$. W. $\left(23 \pm 1^{\circ} \mathrm{C}\right)$ significantly reduced the infestation level of $M$. sebastis in rockfish.
In the present experiment, mebendazole administered orally at a dose of $100 \mathrm{mg} / \mathrm{kg} \mathrm{B}$. W. $\left(20 \pm 1^{\circ} \mathrm{C}\right)$ significantly reduced the number of $M$. sebastis, also, and at a dose of $200 \mathrm{mg} / \mathrm{kg} \mathrm{B}$. W. $\left(20 \pm 1^{\circ} \mathrm{C}\right)$ completely eradicated $M$. sebastis from the gills of juvenile rockfish. Therefore it is indicated that oral administration of praziquantel and mebendazole can be used practically in netpen-culture of rockfish as an effective control measure for M. sebastis infestations without imposing handling related stress to fish.

The efficacy of praziquantel in treatment of $M$. sebastis was not significantly affected by water temperature but that of mebendazole was affected significantly. Elevated temperature apparently enhanced the efficacy of mebendazole against $M$. sebastis infestation. This was also shown by Buchmann et al. (1992) for gill monogeneans on European eel, Anguilla anguilla. Temperature-related variations in pharmacokinetic properties of antibiotics in fish have been previously demonstrated in several studies (Borgan et al., 1981), but the effects of temperature on the mode of action of praziquantel and mebendazole in fish administered orally are not known. Our results indicate that praziquantel can be used at both high and low water temperatures to orally treat $M$. sebastis infestation, and mebendazole can be used at a high water temperature to get high efficacy against $M$. sebastis infestation.

Experimental fish were infected not only with adult parasites, but also with immature ones. There was no big differences in the susceptibility of the parasite at different developmental stages to the chemotherapeutants tested (data not shown).

Buchmann et al. (1992) demonstrated that extended 
exposures to subtherapeutic dosages of mebendazole resulted in drug resistant parasite populations and it was recommended by these authors to alternate between mebendazole and praziquantel treatments in order to delay the emergence of anthelminthic resistance. Indeed, our experiments suggest that development of the drug resistance in $M$. sebastis can be prevented or delayed by alternation in use between praziquantel and mebendazole.

Although Mellergaard et al. (1990) and Iosifidou et al. (1997) reported the residues of mebendazole in eel after bath treatment, no work has been done on the metabolism and excretion of mebendazole and praziquantel in fish administered orally. Regarding safety for the human consumption, therefore, it would be recommended that the oral administration of these chemotherapeutants should be limited to juveniles of rockfish until the residue depletion times of these compounds from flesh of fish are determined.

Although eradication of the parasite from the gills of rockfish was successful in the present experiments, we have the problem of reinfection in the field. We have to establish the retreatment scheme for net-pen cultured rockfish. Experiments on the determination of the retreatment interval is now in progress.

\section{Acknowledgement}

This study was supported by a grant from the Ministry of Maritime Affairs and Fisheries, Republic of Korea.

\section{References}

Andrews, P., H. Thomas, R. Pohlke and J. Seubert (1983): Praziquantel. Med. Res. Rev., 3, 147-200.

Borgan, A., S. A. Odegaard and T. Bergsjo (1981): Temperature-related absorption and excretion of sulphadimidine in rainbow trout, Salmo gairdneri. $\quad$ Acta Vet. Scand., 22, 211217.

Buchmann, K. (1987): Effects of praziquantel on the monogenean gill parasite Pseudodactylogyrus bini. Acta Vet. Scand., 28, 447-450.

Buchmann, K. (1993): Epidemiology and control of Pseudodactylogyrus infections in intensive eel culture systems: Recent trends. Bull. Fr. Peche Piscic., 328, 66-73.

Buchmann, K. and J. Bjerregaard (1990): Mebendazole treatment of pseudodactylogyrosis in an intensive eel-culture system. Aquaculture, 86, 139-153.

Buchmann, K., C. Székely and J. Bjerregaard (1990): Treatment of Pseudodactylogyrus infestations of Anguilla anguilla II. Trials with bunamidine, praziquantel and levamisole. Bull. Eur. Ass. Fish Pathol., 10, 18-120.

Buchmann, K., A. Roepstorff and P. J. Waller (1992): Experimental selection of mebendazole resistant gill monogeneans from the European eel, Anguilla anguilla. J. Fish Dis., 15, 393-400.

Bylund, G. and O. Sumari (1981): Laboratory tests with droncit against diplostomiasis in rainbow trout, Salmo gairdneri Richardson. J. Fish Dis., 4, 259-264.

Chan, B. and B. Wu (1984): Studies on the pathogenicity, biology and treatment of Pseudodactylogyrus for the eels in fishfarms. Act. Zool. Sinica, 30, 173-180.

Goven, B. A. and D. F. Amend (1982): Mebendazole/trichlorfon combination: A new anthelminthic for removing monogenetic trematodes from fish. J. Fish Biol., 20, 373378.

Imada, R. and K. Muroga (1979): Pseudodactylogyrus microrchis (Monogenea) on the gills of cultured eels. III. Experimental control by trichlorfon. Bull. Jpn. Soc. Sci. Fish., 45, 25-29.

Iosifidou, E. G., N. Haagsma, M. Olling, J. H. Boon and M. W. T. Tanck (1997): Residue study of mebendazole and its metabolites hydroxy-mebendazole and amino-mebendazole in eel (Anguilla anguilla) after bath treatment. Drug Metabol. Disp., 25, 317-320.

Kabata, Z. (1985): Parasites and diseases of fish cultured in the tropics. Taylor \& Francis, London. 318 p.

Kim, K. H. and E. S. Choi (1998): Treatment of Microcotyle sebastis (Monogenea) on the gills of cultured rockfish (Sebastes schelegeli) with oral administration of mebendazole and bithionol. Aquaculture, 167, 115-121.

Lorio, W. J. (1989): Experimental control of metacercariae of yellow grub (Clinostomum marginatum) in channel catfish. J. Aquat. Anim. Health, 1, 269-271.

Margolis, L., G. W. Esch, J. C. Holmes, A. M. Kuris and G. A. Schad (1982): The use of ecological terms in parasitology (report of an ad hoc committee of the American Society of Parasitologists). J. Parasitol., 68, 131-133.

Mellergaard, S. (1990): Mebendazole treatment against Pseudodactylogyrus infections in eel (Anguilla anguilla). Aquaculture, 91, 15-21.

Mellergaard, S., K. Buchmann and J. Bjerregaard (1990): Mebendazole residues in eels after anthelminthic treatment in intensive eel-culture systems. In "Residues of Veterinary Drugs in Food. Proceedings of the Euroresidue conference, Nordwijkerhout, The Netherlands" (ed. By N. Haagsma, A. Ruiter and P. B. Czedik-Eysenberg). Department of Science of Food of Animal Origin, University of Utrecht, Utrecht.

Moser, M., J. Sakanari and R. Heckmann (1986): The effects of praziquantel on various larval and adult parasites from freshwater and marine snails and fish. J. Parasitol., 72, 175-176.

Pool, D., K. Ryder and C. Andrews (1984): The control of Bothriocephalus acheilognathi in grass carp, Ctenopharyngodon idella, using praziquantel. Fish. Manag., 15, 31-33.

Roberson, E. L. (1982): Antinematodal drugs. Anticestodal and antitrematodal drugs. In "Veterinary pharmacology 
and therapeutics" (ed. By N. H. Booth and L. E. McDonald). Iowa State University Press, Ames, pp. 803-891.

Sanmartin Duran, M. L., F. Caamano-Garcia, J. Fernendez Casal, J. Leiro and F. M. Ubeira (1989): Anthelminthic activity of praziquantel, niclosamide, netobimin and mebendazole against Bothriocephalus scorpii naturally infecting turbot (Scophthalmus maximus). Aquaculture, 76, 199-201.

Schmahl, G. and H. Mehlhorn (1985): Treatment of fish parasites. 1. Praziquantel effective against monogenea (Dactylogyrus vastator, Dactylogyrus extensus, Diplozoon paradoxum). Z. Parasitenk., 71, 727-737.

Székely, C. and K. Molnár (1987): Mebendazole is an efficacious drug against pseudodactylogyrosis in the European eel
(Anguilla anguilla). J. Appl. Ichthyol., 3, 183-186.

Székely, C. and K. Molnár (1990): Treatment of Ancylodiscoides vistulensis monogenean infestations of the European catfish (Silurus glanis). Bull. Eur. Ass. Fish Pathol., 10, 74-77.

Thoney, D. A. (1990): The effects of trichlorfon, praziquantel and copper sulphate on various stages of the monogenean Benedeniella posterocolpa, a skin parasite of the cownose ray, Rhinoptera bonasus (Mitchill). J. Fish Dis., 13, 385389.

Thoney, D. A. and W. J. Hargis, Jr. (1991): Monogenea (Platyhelminthes) as hazards for fish in confinement. Ann. Rev. Fish Dis., 1, 133-153. 